\title{
СИСТЕМНЫЕ ГЕМОСТАТИЧЕСКИЕ И ПРОТРОМБОТИЧЕСКИЕ ЭФФЕКТЫ ФИБРИН-МОНОМЕРА В ЭКСПЕРИМЕНТЕ ПРИ ДОЗИРОВАННОЙ ТРАВМЕ ПЕЧЕНИ
}

\author{
Андрей Павлович МОМОТ ${ }^{1,3}$, Вячеслав Михайлович ВДОВИН ${ }^{2,3}$, \\ Игорь Ильич ШАХМАТОВ ${ }^{2,3}$, Игорь Геннадьевич ТОЛСТОКОРОВ 4 , \\ Дмитрий Андреевич ОРЕХОВ 5 , Валентин Олегович ШЕВЧЕНКО ${ }^{4}$, \\ Наталья Александровна ЛЫЧЁВА ${ }^{2,3}$, Алексей Владимирович КУДИНОВ \\ Галина Геннадьевна БЕЛОЗЕРСКАЯ
}

${ }^{1}$ Национальный медицинский исследовательский центр гематологии Минздрава России, Алтайский филиал

656045, Россия, г. Барнаул, ул. Ляпидевского, 1

${ }^{2}$ Алтайский государственный медицинский университет Минздрава России 656038, Россия, г. Барнаул, просп. Ленина, 40

${ }^{3}$ НИИ физиологии и фундаментальной медицины 630117, Россия, г. Новосибирск, ул. Тимакова, 4

${ }^{4}$ ООО КДЦ «Добрый доктор» 656006, Россия, г. Барнаул, ул. Балтийская, 4 а

${ }^{5}$ Алтайский краевой кардиологический диспансер 656055, Россия, г. Барнаул, ул. Малахова, 46

${ }^{6}$ Национальный медицинский исследовательский иентр гематологии Минздрава России 125167, г. Москва, Новый Зыковский проезд, 4

Цель исследования - оценить системные гемостатические и протромботические эффекты фибрин-мономера (ФМ) при его внутривенном введении в эксперименте. Материал и методы. В работе использовали 82 кролика-самца породы «Шиншилла» массой 3-4 кг. Наряду с плацебо животным внутривенно вводили водный раствор ФМ в дозах 0,1, 0,25, 0,5, 1,0, 2,5 и 5,0 мг/кг, через 1 ч наносили стандартную травму печени и оценивали кровопотерю (в \% от объема циркулирующей крови), возникшую в результате паренхиматозного кровотечения.

\footnotetext{
Момот А.П. - д.м.н., проф., директор, старший научный сотрудник лаборатории физиологии и патологии гемостаза и гемодинамики, е-тail: xyzan@yandex.ru, http://orcid.org/0000-0002-8413-5484

Вдовин В.М. - к.м.н., доцент, зав. кафедрой патологической физиологии, стариий научный сотрудник лаборатории физиологии и патологии гемостаза и гемодинамики, е-таil: erytrab@gmail.com, https://orcid.org/0000-0002-4606-3627

Шахматов И.И. - д.м.н., дочент, зав. кафедрой нормальной физиологии, стариий научный сотрудник лаборатории физиологии и патологии гемостаза и гемодинамики, e-тail: iish59@yandex.ru, https://orcid.org/0000-0002-0979-8560

Толстокоров И.Г. - хирург, e-mail: igorka69@yandex.ru.https://orcid.org/0000-0001-5406-9191

Орехов Д.А. - хирург, e-mail: orekhoffs@mail.ru, https://orcid.org/0000-0003-0644-6313

Шевченко В.О. - хирург, e-mail: valentin_shevche@mail.ru, https://orcid.org/0000-0002-3471-3426

Лычёва Н.А. - к.б.н., дочент кафедры нормальной физиологии, младиий научный сотрудник лаборатории физиологии и патологии гемостаза и гемодинамики, е-таil: natalia.lycheva@yandex.ru, https://orcid.org/0000-0002-6488-340X

Кудинов А.В. - к.б.н., доиент кафедры фармакологии, е-mail: kudinovalexej@gmail.com, https://orcid.org/0000-0002-0967-6117

Белозерская Г.Г. - д.м.н., зав. лабораторией, e-mail: Belozerskaya.G@blood.ru, http://orcid.org/0000-0001-8620-153X

Киселёв В.И. - д.м.н., чл.-корр. РАН, проф. кафедры нормальной физиологии, зав. лабораторией, главный научный сотрудник лаборатории физиологии и патологии гемостаза и гемодинамики, e-mail: vik@agmu.ru,https://orcid.org/0000-0003-2683-3118
} 
Исследование системы гемостаза включало в себя оценку числа тромбоцитов в венозной крови, уровней фибриногена и D-димера в плазме крови. Результаты и их обсуждение. Кровопотеря после дозированной травмы при введении плацебо составила $10,0[4,0 ; 15,7]$ \% объема циркулирующей крови (медиана [25-й процентиль; 75 -й процентиль]). Введение ФМ в дозах $0,25,2,5$ и 5,0 мг/кг приводило к уменьшению кровопотери в 6,3 $(p<0,001), 7,8(p<0,001)$ и 2,7 раза $(p=0,04)(1,6[1,0 ; 3,0], 1,3[0,6 ; 1,6]$ и $3,7[2,8 ; 5,5]$ \% объема циркулирующей крови соответственно). В высоких дозах (2,5 и 5,0 мг/кг) ФМ минимизировал кровопотерю за счет активации коагуляционных свойств крови и тромбообразования, что иллюстрировалось 7-8-кратным ростом уровня D-димера (в сравнении с плацебо). Применение ФМ в дозе 0,25 мг/кг не сопровождалось увеличением содержания D-димера, хотя и многократно уменьшало кровопотерю. Заключение. Полученные данные свидетельствуют о наличии у низкодозированного ФМ (0,25 мг/кг) уникальных гемостатических свойств, открывают возможности к созданию нового поколения гемостатических препаратов системного действия.

Ключевые слова: система гемостаза, фибрин-мономер, травма печени, паренхиматозное кровотечение, гемостатический эффект, кролики.

Обширные травмы относят к неотложным состояниям, которые, как правило, сопровождаются тяжелыми кровотечениями, нередко с формированием геморрагического шока, что представляет собой серьезную угрозу для здоровья и жизни людей [16]. В рамках данной проблемы внимание исследователей привлечено к поиску новых и эффективных способов управления травма-ассоциированной кровопотери, в том числе на фоне действия известных антитромботических препаратов [12]. В настоящее время в медицинской практике используется ряд лекарственных препаратов, обладающих доказанным и объяснимым системным гемостатическим действием [14]. Их эффективность обусловлена усилением коагуляционных свойств крови/тромботического потенциала, что, помимо терапевтического эффекта, не исключает риск развития артериальных или венозных тромбозов $[11,16]$. Данное обстоятельство способствует поиску инновационных, сравнительно более безопасных препаратов, обладающих системным кровоостанавливающим действием.

В основе механизмов, приводящих к остановке кровотечения при травме, лежит образование тромба (сгустка фибрина, содержащего клетки крови). Последний формируется, как известно, в результате взаимодействия тромбина (фактора IIa) с фибриногеном в ходе реакций самосборки фибрин-мономера (ФМ), лишенного фибринопептидов А и В $[2,4]$. Интерес к системному применению ФМ в эксперименте in vivo и оценке его влияния на систему гемостаза возник около 50 лет назад, что иллюстрируется работой Б.А. Кудряшова и соавт. [3]. По ее результатам установлена прямая связь введения в кровоток экспериментальных животных экзогенного ФМ (25 мг/кг и более) с массированным тромбообразованием магистральных сосудов и летальностью. Ранее, с нашим участием, продемонстрировано, что значительно меньшие дозы ФМ (от 0,5 до 5,0 мг/кг), вводимые внутривенно, совместимы с жизнью животных [5], однако анализа биологических свойств ФМ в данной работе проведено не было. Целью настоящего исследования явилась оценка системных гемостатических и протромботических эффектов ФМ при его внутривенном введении животным на фоне дозированной травмы печени.

\section{МАТЕРИАЛ И МЕТОДЫ}

Работа включала в себя два этапа. Первый был посвящен исследованиям лиофилизированного препарата ФМ, полученного из плазмы крови человека в соответствии с ранее зарегистрированной технологией [6], второй - проведению экспериментальных исследований in vivo. Исследования на животных проводили в соответствии с Европейской конвенцией и директивами по охране позвоночных животных, используемых в эксперименте, 86/609/EЕC, а также Хельсинкской декларацией и «Правилами проведения работ с использованием экспериментальных животных» [10]. Работа одобрена локальным этическим комитетом Алтайского государственного медицинского университета.

Анализ ФМ предусматривал:

- характеристику ФМ по молекулярной масcе $\alpha$-, $\beta$ - и $\gamma$-цепей с помощью денатурирующего электрофореза в полиакриламидном геле в присутствии додецилсульфата натрия по методу U.K. Laemmli [13];

- оценку иммунологического сходства ФМ и фибриногена человека («Sigma-Aldrich», США) методом иммуноблоттинга с использованием оборудования и реагентов фирмы «Bio-Rad» по технологии, описанной G.L. Soe et al. [17];

- исследование на наличие примесей тромбина (фактора ІІа) в препарате ФМ по измерению скорости гидролиза хромогенного субстрата тромбином (при 405 нм) на спектрофотометре 
«Photometer 5010 v5+» («Robert Riele GmbH Co

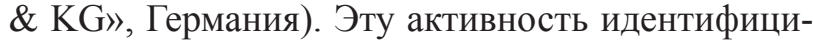
ровали в смеси водного раствора ФМ (11,0 мг/ мл) и специфичного к тромбину «Tos-Gly-ProArg-ANBA-IPA» («Siemens AG», Германия) хромогенного субстрата, взятого в концентрации 2,0 ммоль/л. Параллельно такая активность определялась в растворах плацебо и тромбина человека (3 NIH ед/мл, «Технология-Стандарт», Россия).

Работы, посвященные изучению системных гемостатических и протромботических эффектов $\Phi М$, проведены на 82 кроликах-самцах породы «Шиншилла» массой 3,0-4,0 кг. С использованием генератора случайных чисел статистической программы Statistica 10 («StatSoft», США) были сформированы 7 групп экспериментальных животных. В первую группу вошли животные, кторым ввели в краевую вену уха плацебо $(4,0 \mathrm{M}$ раствор мочевины, соответствующий ее концентрации в растворе ФМ), группы 2-7 составили животные, которым внутривенно вводили раствор ФМ в дозах $0,1,0,25,0,5,1,0,2,5$ и 5,0 мг/кг массы тела соответственно. Забор крови проводили после надреза краевой вены уха в пробирку, содержащую 0,11 М (3,8\%-й) раствор цитрата натрия (соотношение крови и цитрата $9: 1$ ). Стабилизированную цитратом кровь центрифугировали при 1200 g в течение 15 минут, полученную обедненную тромбоцитами плазму использовали для исследования системы гемостаза. Кровь забиралась дважды: до внутривенного введения при помощи иглы-катетера «Cathy» (фирма «HMD») препаратов (раствора плацебо и ФМ), а также спустя 1 ч после инъекции - перед нанесением дозированной травмы печени.

Дозированную травму печени у наркотизированных кроликов проводили в соответствии с имеющимися рекомендациями [8]. Объем кровопотери устанавливали в \% от объема циркулирующей крови с учетом массы тела животных [7-9].

Исследование системы гемостаза включало в себя оценку числа тромбоцитов в венозной крови с использованием гематологического анализатора «Drew3» («Drew Scientific Group», CШA), концентрации фибриногена на коагулометре «Thrombostat 2» («Behnk Elektronik», Германия) с применением набора реагентов «Тех-Фибриногентест» («Технология-Стандарт», Россия) и уровня D-димера в плазме крови (тест-система «NycoCard ${ }^{\mathbb{R}}$ D-Dimer», «Axis-Shield PoC AS», Hopвегия) с использованием анализатора-рефлектометра «NycoCard Reader II» («Axis-Shield PoC AS»).

Распределение признаков в выборках оценивали по критерию Шапиро - Уилка. В зависимости от распределения признаков использовали $t$-критерий Стьюдента или $U$-критерий Манна Уитни, а также $F$-критерий Фишера для оценки дисперсий выборок. Различия считали достоверными при уровне статистической значимости $p \leq 0,05$.

\section{РЕЗУЛЬТАТЫ}

Анализ фибрин-мономера. Из рис. 1 видно, что молекулярная масса $\alpha$-, $\beta$ - и $\gamma$-цепей коммерческого фибриногена, определенная в ходе гель-электрофореза, соответствует литературным данным [15]. При этом $\gamma$-цепи фибриногена и ФМ не различались по молекулярной массе, в то время как молекулярная масса $\alpha$ - и $\beta$-цепей $Ф \mathrm{M}$ была меньше, чем у $\alpha$ - и $\beta$-цепей фибриногена. Полученная разница примерно соответствовала потере молекулой ФМ двух фибринопептидов А (CAS No. 25422-31-5) - 1536 Да и двух фибринопептидов B (CAS No. 36204-23-6) - 1552 Да. Таким образом, была подтверждена принадлежность исследуемого препарата ФМ к дез-ААВВфибриногену с учетом ранее выполненных фундаментальных исследований $[1,4]$.

В результате переноса и детекции при помощи поликлональных кроличьих антител против фибриногена человека на мембране при длительной экспозиции в образцах коммерческого фибриногена и препарата ФМ обнаружено по два

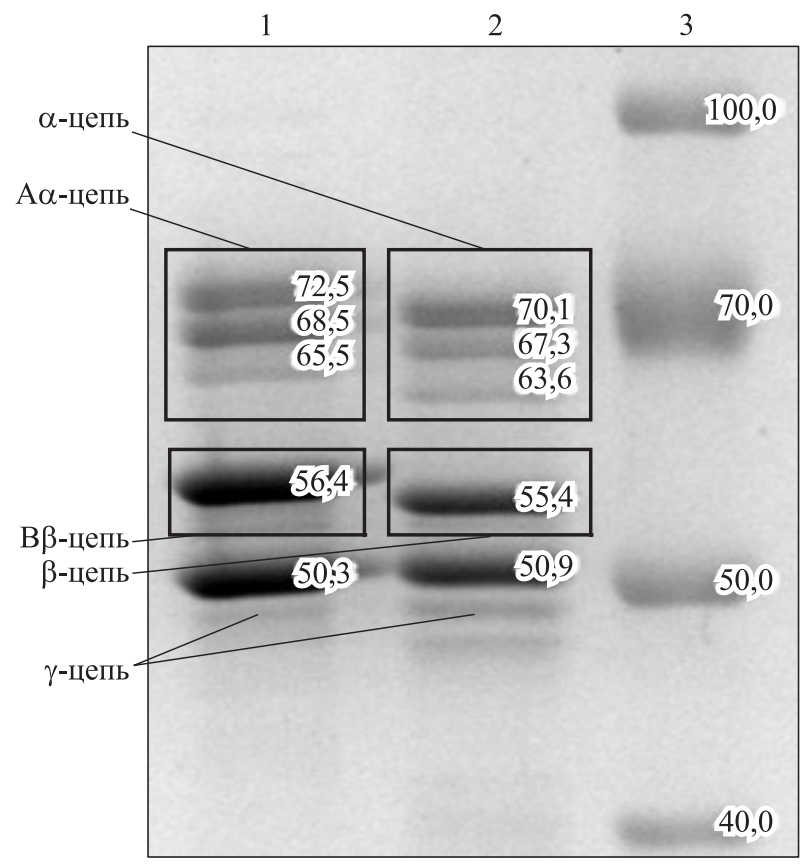

Pис. 1. Электрофореграммы полипептидных ичепей

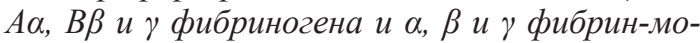
номера. 1 - трек коммерческого фибриногена (кДа); 2 - трек фибрин-мономера (кДа); 3 трек смеси маркерных белков с известной молекулярной массой (кДа) 
Момот А.П. и др. Системные гемостатические и протромботические эффекты... /c. 6-12

Таблица 1

Динамика поглощения в смесях исследуемого образиа с хромогенным субстратом, усл. ед.

\begin{tabular}{|l|c|c|c|}
\hline \multicolumn{1}{|c|}{ Образец } & 0 мин & Через 2 мин & Динамика \\
\hline Плацебо & 0,180 & 0,178 & $-0,002(2 \%)$ \\
\hline Препарат ФМ & 0,220 & 0,216 & $-0,004(3 \%)$ \\
\hline Тромбин (3 NIН ед/мл) & 0,220 & 0,746 & $+0,256(339 \%)$ \\
\hline
\end{tabular}

пятна, соответствующих $\alpha$ - и $\beta$-цепям сравниваемых молекул, следовательно, сравниваемые препараты иммунологически сопоставимы.

Учитывая применение тромбина человека в технологии изготовления ФМ [6], проведено исследование по оценке возможной амидолитической тромбиновой активности раствора ФМ (в сравнении с растворами плацебо и тромбина). Данные, приведенные в табл. 1, свидетельствуют о том, что растворы плацебо и ФМ не обладают сколько-нибудь значимой тромбиновой активностью.

Результаты экспериментальных исследований in vivo. При проведении дисперсионного анализа полученных данных показано, что пошаговое увеличение дозы вводимого ФМ от 0,1 до 5,0 мг/кг оказало статистически значимое влияние на изменение объема кровопотери $(F=3,92$, $p<0,001)$. В частности, установлено, что наиболее низкая доза ФМ $(0,1$ мг/кг) при сравнении с плацебо практически не влияла на объем кровопотери (рис. 2). В то же время применение ФМ в дозах $0,25,2,5$ и 5,0 мг/кг (в сравнении с плацебо) приводило к уменьшению посттравматической

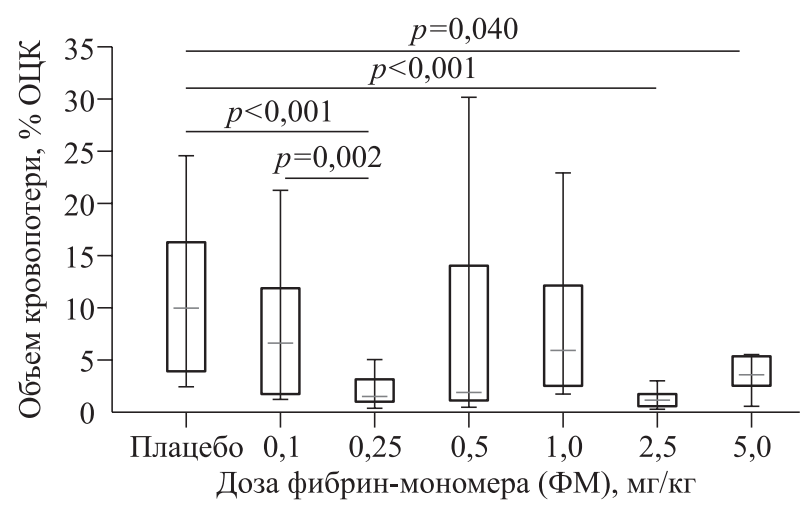

Puc. 2. Объем кровопотери (\% ОЦК) в группах сравнения после дозированной травмы печени. ОЦК - объем ичиркулирующей крови; значения представлень в виде медиань - горизонтальной линии внутри прямоугольника, нижней и верхней границей которого служат соответственно 25-й и 75-й процентили, и значений, соответствующих прочентилям 2,5 и 97,5 нижний и верхний концьь «усов» кровопотери, по медиане, соответственно в 6,3 $(p<0,001), 7,8(p<0,001)$ и 2,7 раза $(p=0,04)$.

В работе не выявлено сколько-нибудь значимое снижение числа тромбоцитов и уровня фибриногена (до и после инъекции) во всех сравниваемых группах, за исключением уменьшения, по медиане, на 32,5 \% количества тромбоцитов у животных, получивших максимальную дозу ФМ - 5,0 мг/кг (табл. 2). Наряду с этим установлена связь между дозой вводимого ФМ и уровнем D-димера в плазме крови методом дисперсионного анализа $(F=6,37 ; p<0,001)$. Из табл. 2 также видно, что повышение содержания D-димера наблюдалось после применения ФМ в дозах 2,5 и $5,0 \mathrm{мг/кг.}$

\section{ОБСУЖДЕНИЕ}

В первой части работы, посвященной исследованию коммерческого препарата ФМ, проведена его молекулярная и иммунологическая идентификация. При этом был принят во внимание ряд известных методических подходов $[1,2,4]$. В соответствии с полученными данными было установлено соответствие характеристик принятого в работу препарата известным характеристикам ФМ (дез-ААВВ-фибриногена). Наряду с этим в работе исключено потенциальное влияние на изучаемые гемостатические эффекты следовых концентраций тромбина, поскольку данная коагулаза используется в технологии приготовления препарата ФМ [6].

Во второй части работы изучались системные гемостатические и протромботические свойства ФМ в экспериментах in vivo. Показано, что внутривенное введение ФМ приводит к закономерному уменьшению объема посттравматической кровопотери, однако линейный дозозависимый эффект отсутствовал. Наибольшее снижение данного показателя было связано с использованием трех доз ФМ - 0,25, 2,5 и 5,0 мг/кг. Другие дозы препарата $(0,5$ и 1,0 мг/кг) не оказывали значимого влияния. При этом следует отметить, что высокие дозы вводимого ФМ (2,5 и 5,0 мг/кг) способствовали внутрисосудистому тромбообразованию, что иллюстрировалось увеличением 
Момот А.П. и др. Системные гемостатические и протромботические эффектыл... /c. 6-12

Таблица 2

Показатели системы гемостаза у животных, получивиих плацебо и фибрин-мономер в разных дозах

\begin{tabular}{|c|c|c|c|c|c|c|}
\hline \multirow{2}{*}{ Группа } & \multicolumn{2}{|c|}{$\begin{array}{c}\text { Количество тромбоцитов } \\
\text { в крови, } \times 10^{9} / \text { л }\end{array}$} & \multicolumn{2}{|c|}{ Уровень фибриногена, г/л } & \multicolumn{2}{|c|}{ Уровень D-димера, нг/мл } \\
\hline & до & после & до & после & до & после \\
\hline $\begin{array}{l}\text { Плацебо } \\
(n=11)\end{array}$ & $\begin{array}{c}617,0 \\
{[456,0 \div 760,5]}\end{array}$ & $\begin{array}{c}524,0 \\
{[480,5 \div 686,5]}\end{array}$ & $\begin{array}{c}3,30 \\
{[2,80 \div 4,40]}\end{array}$ & $\begin{array}{c}3,70 \\
{[2,80 \div 4,50]}\end{array}$ & $\begin{array}{c}100,0 \\
{[100,0 \div 100,0]}\end{array}$ & $\begin{array}{c}100,0 \\
{[100,0 \div 175,0]}\end{array}$ \\
\hline $\begin{array}{l}\text { ФМ 0,1 МГ/кг } \\
(n=12)\end{array}$ & $\begin{array}{c}592,5 \\
{[511,8 \div 666,3]}\end{array}$ & $\begin{array}{c}531,0 \\
{[465,0 \div 609,8]}\end{array}$ & $\begin{array}{c}3,70 \\
{[3,40 \div 3,80]}\end{array}$ & $\begin{array}{c}3,50 \\
{[3,00 \div 3,90]}\end{array}$ & $\begin{array}{c}150,0 \\
{[100,0 \div 200,0]}\end{array}$ & $\begin{array}{c}200,0 \\
{[175,0 \div 300,0]}\end{array}$ \\
\hline $\begin{array}{l}\Phi \mathrm{M} 0,25 \mathrm{M \Gamma} / \mathrm{К} \\
(n=15)\end{array}$ & $\begin{array}{c}526,0 \\
{[464,3 \div 602,8]}\end{array}$ & $\begin{array}{c}524,0 \\
{[452,0 \div 600,5]}\end{array}$ & $\begin{array}{c}3,75 \\
{[2,80 \div 4,45]}\end{array}$ & $\begin{array}{c}3,40 \\
{[2,80 \div 4,80]}\end{array}$ & $\begin{array}{c}100,0 \\
{[100,0 \div 175,0]}\end{array}$ & $\begin{array}{c}100,0 \\
{[100,0 \div 200,0]}\end{array}$ \\
\hline $\begin{array}{l}\text { ФМ 0,5 Мг/кГ } \\
(n=12)\end{array}$ & $\begin{array}{c}595,0 \\
{[562,0 \div 718,0]}\end{array}$ & $\begin{array}{c}606,0 \\
{[554,5 \div 633,5]}\end{array}$ & $\begin{array}{c}2,80 \\
{[2,20 \div 3,00]}\end{array}$ & $\begin{array}{c}2,60 \\
{[2,28 \div 2,85]}\end{array}$ & $\begin{array}{c}100,0 \\
{[100,0 \div 100,0]}\end{array}$ & $\begin{array}{c}100,0 \\
{[100,0 \div 100,0]}\end{array}$ \\
\hline 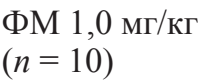 & $\begin{array}{c}572,0 \\
{[510,0 \div 647,0]}\end{array}$ & $\begin{array}{c}544,0 \\
{[455,5 \div 592,0]}\end{array}$ & $\begin{array}{c}2,90 \\
{[2,50 \div 3,90]}\end{array}$ & $\begin{array}{c}3,20 \\
{[2,60 \div 3,80]}\end{array}$ & $\begin{array}{c}100,0 \\
{[100,0 \div 100,0]}\end{array}$ & $\begin{array}{c}200,0 \\
{[100,0 \div 200,0]}\end{array}$ \\
\hline $\begin{array}{l}\text { ФМ 2,5 мГ/кг } \\
(n=13)\end{array}$ & $\begin{array}{c}551,5 \\
{[437,3 \div 600,5]}\end{array}$ & $\begin{array}{c}479,0 \\
{[403,5 \div 568,3]}\end{array}$ & $\begin{array}{c}3,25 \\
{[2,59 \div 3,93]}\end{array}$ & $\begin{array}{c}3,20 \\
{[2,60 \div 3,35]}\end{array}$ & $\begin{array}{c}100,0 \\
{[100,0 \div 200,0]}\end{array}$ & $\begin{array}{c}700,0^{*} \\
{[500,0 \div 800,0]}\end{array}$ \\
\hline $\begin{array}{l}\text { ФМ 5,0 Мг/кг } \\
(n=9)\end{array}$ & $\begin{array}{c}607,0 \\
{[500,0 \div 631,0]}\end{array}$ & $\begin{array}{c}410,0^{\#} \\
{[353,0 \div 566,0]}\end{array}$ & $\begin{array}{c}2,80 \\
{[2,55 \div 3,20]}\end{array}$ & $\begin{array}{c}3,00 \\
{[2,85 \div 3,80]}\end{array}$ & $\begin{array}{c}100,0 \\
{[100,0 \div 100,0]}\end{array}$ & $\begin{array}{c}800,0^{\wedge} \\
{[550,0 \div 1100,0]}\end{array}$ \\
\hline
\end{tabular}

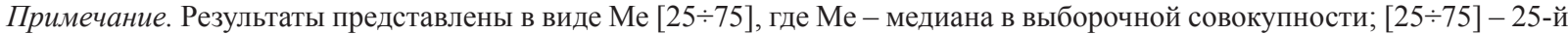
и 75-й процентили; $n$ - количество особей в группе; «до» - показатели до введения ФМ или плацебо, «после» - показатели через 1 ч после введения ФМ или плацебо; обозначены статистически значимые отличия от величин соответствующих показателей до введения ФМ или плацебо: * - при $p=0,002, \#-$ при $p=0,04,{ }^{\wedge}-$ при $p=0,01$.

уровня D-димера в плазме крови наряду со снижением числа тромбоцитов (при применении ФМ в дозе 5,0 мг/кг). В последнем случае при массивном тромбозе (тромботические отложения в аорте и сосудах легких) погибло одно из 11 животных.

Отмеченные в работе протромботические эффекты высоких доз ФМ (2,5-5,0 мг/кг) могут быть вполне объяснимы, поскольку, как отмечалось выше, ФМ в достаточных концентрациях в плазме крови представляет собой классическую основу для фибринообразования и формирования тромба. И с этим согласуется их способность уменьшать кровопотерю при дозированной травме печени. Однако факт снижения объема потерянной крови при применении в 10-20 раз меньшей дозы ФМ $(0,25$ мг/кг), не сопровождаемого потреблением тромбоцитов и увеличением уровня D-димера, может рассматриваться как феномен, не имеющий в настоящее время своего объяснения.

Можно принять также во внимание, что после внутривенного введения ФМ в дозе 0,25 мг/кг его расчетная концентрация в плазме крови составляет около 0,007 г/л, в то время как концентрация собственного фибриногена у экспериментальных животных варьирует в диапазоне от 3,3 до 3,7 г/л по медиане (см. табл. 2). Сопоставляя уровни этих белков $(1: 470-1: 530)$ в плазме крови, можно утверждать, что введенный ФМ (в дозе 0,25 мг/кг) не способен самостоятельно форми- ровать фибриновые сгустки, и индуцированный им гемостатический эффект имеет другую, не известную пока природу.

\section{ЗАКЛЮЧЕНИЕ}

Выявленный в работе системный гемостатический эффект ФМ (в дозе 0,25 мг/кг), не сопровождающийся активацией свертывающей системы крови, может послужить основой для создания нового поколения гемостатиков. В продолжение исследований и для расшифровки механизмов действия ФМ предполагается анализ его гемостатических свойств на моделях у животных со сниженным гемостатическим потенциалом на фоне применения представителей различных групп антитромботических препаратов.

\section{КОНФЛИКТ ИНТЕРЕСОВ}

Авторы декларируют отсутствие явных и потенциальных конфликтов интересов, связанных с публикацией настоящей статьи.

\section{БЛАГОДАРНОСТИ}

Научные исследования, результаты которых изложены в статье, выполнены при финансовой поддержке РФФИ (в рамках гранта на реализацию научного проекта № 18-415-220001). 


\section{СПИСОК ЛИТЕРАТУРЫ}

1. Белииер В.А., Вареикая Т.В. Фибриноген и фибрин: строение молекул, самосборка волокон // Успехи соврем. биологии. 1975. 80. (1). 5-21.

2. Зубаиров Д.М. Молекулярные основы свертывания крови и тромбообразования. Казань: Фэн, 2000. $367 \mathrm{c}$.

3. Кудряшов Б.А., Молчанова Л.В., Калишевская Т.М., Базазьян Г.Г., Пасторова В.Е., Сытина Н.П. О функциональном состоянии противосвертывающей системы при внутривенном введении фибрин-мономера // Вопр. мед. химии. 1969. XV. (5). 483-486.

4. Луговской Э.В., Макогоненко Е.М., Комисаренко C.B. Молекулярные механизмы образования и разрушения фибрина: физико-химический и иммунохимический анализ. Киев: Наук. думка, 2013. $230 \mathrm{c}$.

5. Макаров В.А., Белозерская Г.Г., Момот А.П., Соколов Э.А., Тер-Арутюняни А.А., Васильева Т.М. Гемостатическое средство. Пат. 2308287 РФ; опубл. 20.10.2007.

6. Момот А.П., Шахматов И.И., Ломаев И.С., Терехов С.С. Способ промышленного получения фибрин-мономера из плазмы крови. Пат. 2522237 РФ; опубл. 15.05.2014.

7. Руководство по проведению доклинических исследований лекарственных средств. Часть первая / ред. А.Н. Миронов. М.: Гриф и К, 2012. 944 с.

8. Руководство по экспериментальному (доклиническому) изучению новых фармакологических веществ / ред. Р.Ю. Хабриев. М.: Медицина, 2005. $832 \mathrm{c}$.

9. Справочник. Физиологические, биохимические и биометрические показатели нормы экспери- ментальных животных / ред. В.Г. Макаров. СПб.: ЛЕМА, 2013. $116 \mathrm{c}$.

10. European convention for the protection of vertebrate animals used for experimental and other scientific purposes. Strasburg: Council of Europe, 1986. $11 \mathrm{p}$.

11. Damage Control Resuscitation at Level IIb/ III Treatment Facilities / Joint Theater Trauma System Clinical Practice Guideline. Feb. 2013. 32 p.

12. Dreijer A.R., Kruip M.J., Diepstraten J., Polinder S., Brouwer R., Leebeek F.W., Vulto A.G., Bemt P.M. Antithrombotic stewardship: a multidisciplinary team approach towards improving antithrombotic therapy outcomes during and after hospitalisation: a study protocol // BMJ Open. 2016. 6. (12). e011537.

13. Laemmli U.K. Cleavage of structural proteins during the assembly of the head of bacteriophage T4 // Nature. 1970. 227. (5259). 680-685.

14. Levi M. Management of bleeding in patients treated with direct oral anticoagulants // Crit. Care. 2016. 20. 249.

15. Putnam F.W. The Plasma Proteins. 2nd ed. Vol. 2. N.Y.: Acad. Press, 1975. 148 p.

16. Rossaint R., Bouillon B., Cerny V., Coats T.J., Duranteau J., Fernández-Mondéjar E., Filipescu D., Hunt B.J., Komadina R., Nardi G., Neugebauer E.A., Ozier Y., Riddez L., Schultz A., Vincent J.L., Spahn D.R. The European guideline on management of major bleeding and coagulopathy following trauma: fourth edition // Crit. Care. 2016.12. (20). 100.

17. Soe G.L., Kohno I., Inuzuka K., Itoh Y., Matsuda $M$. A monoclonal antibody that recognizes a neoantigen exposed in the E domain of fibrin monomer complexed with fibrinogen or its derivatives: its application to the measurement of soluble fibrin in plasma // Blood. 1996. 188. (6). 2109-2117. 


\title{
SYSTEMIC HEMOSTATIC AND PROTHROMBOTIC EFFECTS OF FIBRIN-MONOMER IN EXPERIMENT WITH DOSED LIVER THERAPY
}

\begin{abstract}
Andrey Pavlovich MOMOT ${ }^{1,3}$, Vyacheslav Mikhaylovich VDOVIN, ${ }^{2,3}$, Igor Ilyich SHAKHMATOV ${ }^{2,3}$, Igor Gennadievich TOLSTOKOROV ${ }^{4}$, Dmitriy Andreevich OREKHOV 5 , Valentin Olegovich SHEVCHENKO ${ }^{4}$, Natalya Alexandrovna LYCHEVA ${ }^{2,3}$, Alexey Vladimirovich KUDINOV ${ }^{2}$, Galina Gennadievna BELOZERSKAYA ${ }^{6}$, Valeriy Ivanovich KISELEV ${ }^{2,3}$
\end{abstract}

${ }^{1}$ National Research Center for Hematology of Minzdrav of Russia, Altai Branch 656045, Barnaul, Lyapidevskogo str., 1

${ }^{2}$ Altai State Medical University of Minzdrav of Russia 656038, Barnaul, Lenin av., 40

${ }^{3}$ Research Institute of Physiology and Fundamental Medicine 630117, Novosibirsk, Timakov str., 4

${ }^{4}$ Consulting Diagnostic Center «Dobryi Doktor» Ltd. 656006, Barnaul, Baltiyskaya str., 4 a

${ }^{5}$ Altai Regional Cardiology Health Center 656055, Barnaul, Malakhov str., 46

${ }^{6}$ National Research Center for Hematology of Minzdrav of Russia 125167, Moscow, Novyy Zykovsky dr., 4

Objective of the study is to experimentally evaluate system hemostatic and prothrombotic effects of intravenous fibrin monomer (FM). Materials and methods. Eighty two Chinchilla rabbits weighing 3-4 kg were used in the study. In addition to the placebo, animals were administered an aqueous solution of fibrin monomer (FM) intravenously at doses of $0.1,0.25,0.5,1.0,2.5$ and $5.0 \mathrm{mg} / \mathrm{kg}$. After 1 hour, a standard liver injury was performed and the blood loss (\% of the circulating blood volume) resulting from parenchymal hemorrhage was estimated. Hemostatic system examination included platelet number in venous blood and fibrinogen and D-dimer levels in blood plasma. Results and discussion. Blood loss after dosed injury with placebo was 10.0 [4.0; 15.7$] \%$ blood volume (median [25th percentile; 75th percentile]). FM preparation doses of $0.25,2.5$ and $5.0 \mathrm{mg} / \mathrm{kg}$ resulted in a decrease of blood loss by 6.3 ( $p<0.001)$, $7.8(p<0.001)$ and 2.7 times $(p=0.04)(1.6[1.0 ; 3.0], 1.3[0.6 ; 1,6]$ and 3.7 [2.8; 5.3] \% blood volume, respectively). High doses of FM preparation $(2.5$ and $5.0 \mathrm{mg} / \mathrm{kg}$ ) minimized blood loss due to activation of coagulation and thrombus formation, which was illustrated by a 7.0-8.0-fold increase in D-dimer level (compared to placebo). $0.25 \mathrm{mg} / \mathrm{kg}$ of FM preparation did not lead to an increase of D-dimer content, although the blood loss was greatly reduced. Conclusion. The data obtained show the presence of unique hemostatic properties in low-dose FM preparation $(0.25 \mathrm{mg} / \mathrm{kg})$, which allows creating system hemostatic agents of a new generation.

Key words: hemostatic system, fibrin monomer, liver injury, parenchymal hemorrhage, hemostatic effect, rabbits.

Momot A.P. - doctor of medical sciences, professor, director,e-mail: xyzan@yandex.ru

Vdovin V.M. - candidate of medical sciences, associate professor, head of the department of pathological physiology, e-mail: erytrab@gmail.com

Shakhmatov I.I. - doctor of medical sciences, professor, head of the department of normal physiology,

e-mail: iish59@yandex.ru

Tolstokorov I.G. - surgeon, e-mail: igorka69@yandex.ru

Orekhov D.A. - surgeon, e-mail: orekhoffs@mail.ru

Shevchenko V.O. - surgeon, e-mail: valentin_shevche@mail.ru

Lycheva N.A. - candidate of biological sciences, associate professor of the department of normal physiology,

e-mail: natalia.lycheva@yandex.ru

Kudinov A.V. - candidate of biological sciences, associate professor of the department of pharmacology,

e-mail: kudinovalexej@gmail.com

Belozerskaya G.G. - doctor of medical sciences, head of laboratory of pathology and pharmacology of hemostasis,

e-mail: belgalgen53@mail.ru

Kiselev V.I. - corresponding member of RAS, doctor of medical sciences, professor of the department of normal physiology,e-mail: vik@agmu.ru 